\title{
Changes in Conjunctiva Morphology Using Impression Cytology in Patients with Hashimoto's Thyroiditis without Thyroid-Associated Ophthalmopathy
}

\author{
Mustafa ALTAY' (D), Tuğba ŞAHIN² ${ }^{\mathbb{D}}$, Zennure YILDIZ² ${ }^{\mathbb{D}}$, Gülçin ŞiMŞEK ${ }^{3}$ (D), Mehmet ÇITIRIK ${ }^{4}$ (D), İhsan

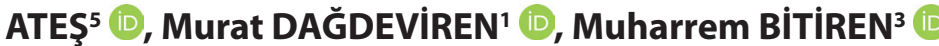 \\ Department of ${ }^{1}$ Endocrinology and Metabolism, ${ }^{2}$ Ophthalmology, ${ }^{3}$ Pathology, University of Health Sciences, \\ Keçiören Health Administration and Research Center, ANKARA, TURKEY, \\ ${ }^{4}$ Department of Ophthalmology, University of Health Sciences, Ulucanlar Health Administration and Research Center, ANKARA, TURKEY \\ ${ }^{5}$ Department of Internal Medicine, University of Health Sciences, Ankara Numune Health Administration and Research Center, ANKARA, TURKEY
}

\begin{abstract}
Objective: To compare the conjunctival morphological changes in patients with Hashimoto's thyroiditis (HT) without thyroid-associated ophthalmopathy (TAO) and controls using impression cytology technique.

Material and Method: We included $25 \mathrm{HT}$ patients and 33 healthy controls who did not have TAO findings or dry eye. For both groups, thyroid stimulating hormone (TSH), free T4(FT4), and anti-thyroid peroxidase (anti-TPO) were measured. Thyroid ultrasonography was performed, together with all routine eye check-ups and the Schirmer's test. Also, conjunctival impression cytology (CIC) test was performed to analyze the conjunctival morphology.
\end{abstract}

Results: When the CIC of HT patients was observed; $12 \%$ had grade $0,40 \%$ had grade $1,28 \%$ had grade 2 and $20 \%$ had grade 3 . While patients with squamous metaplasia made up $48 \%$ of the HT group, this was observed at $6.1 \%$ in the control group (p<0,001). In the regression model formulated, it was observed that obesity $(\mathrm{OR}=7.500 ; \mathrm{p}=0.017)$ and anti TPO levels $(\mathrm{OR}=1.370, \mathrm{p}=0,007)$ were independent stipulations for the squamous metaplasia.

Conclusion: Conjunctival squamous metaplasia was more frequently seen in HT than controls and serum Anti-TPO level and obesity were detected as independent predictors of the worsening at the conjunctival impression cytology.

Key Words: Anti-TPO, Conjunctival impression cytology, Hashimoto's thyroiditis, Inflammation

\section{INTRODUCTION}

Hashimoto's thyroiditis (HT) is one of the most common human autoimmune diseases leading to significant morbidity in women. Also HT is the most common cause of hypothyroidism in iodine-sufficient regions in the world (1). Up to $2 \%$ of the general population is affected by HT and it is more common in elderly women, and ten times more frequently observed in women compared to men (2). Similar to possibly all autoimmune disorders, the noxious interaction between external (environmental and endogenous) and internal (genetic) factors is required to trigger HT. HT results from loss of immune tolerance and reactivity to thyroid auto-antigens: thyroid peroxidase, thyroglobulin and thyroid stimulating hormone receptor (TSHR). This causes the gland to be infiltrated by $\mathrm{T}$ cells and $\mathrm{B}$ cells producing antibodies specific for clinical manifestations. Additionally, T cells included in HT induce

(Turk Patoloji Derg 2019, 35:213-220)

Received : 11.04.2019 Accepted : 10.05.2019 apoptosis in thyroid follicular cells, which ultimately leads to the destruction of the gland (3). A significant proportion of patients are asymptomatic. When anti-thyroid peroxidase (anti-TPO) and/or anti tyhroglobulin (antiTG) was positive in the serum in line with the presence of parenchymal heterogeneity on thyroid ultrasonography, Hashimoto's thyroiditis was diagnosed.

Some changes and signs named as thyroid-associated ophthalmopathy (TAO)' have been described in HT, as in Graves' disease. These are dry eye, upper eyelid retraction, and eye muscle dysfunction as reduced eye movements in upgaze and proptosis $(4,5)$. Only a few cases and studies about HT-associated eye diseases have been reported in the literature $(4,5)$. In previous studies, ocular surface inflammation (Grade 2-3 changes of impression cytology) could be the single present clinical sign in Graves' disease before the onset of overt findings of TAO $(6,7)$.

Correspondence: Murat DAĞDEVIREN

Department of Endocrinology and Metabolism, University of Health Sciences, Keçiören Health Administration and Research Center, ANKARA, TURKEY

E-mail: muratdagdeviren61@hotmail.com Phone: +90 3123569000 
Unfortunately, there is no report about how conjunctival structure is affected in HT. We therefore wondered if we could detect these changes before the development of ophthalmopathy in Hashimoto's thyroiditis. We therefore compared the conjunctival morphological changes in patients with HT without TAO and controls using the impression cytology technique. In addition, we also look into the possible association of conjunctival morphological changes with thyroid hormones and thyroid antibodies.

\section{MATERIAL and METHODS}

First of all, approval was asked for from the hospital ethical commission before the start of the study. The work was conducted according to the principles of the Helsinki Declaration, and a written consent concerning the study was confirmed from each of the participants.

Twenty five patients in total with no known disorder other than Hashimoto's thyroiditis and 33 healthy individuals which were all over 18 years of age were enrolled in the study. Those with an eye disorder correlated to the thyroid were excluded based on their clinical activity scores (CAS) (8) and those with any eye disease such as dry eye or active infection, taking systemic-topical drugs for thyroid disease or for some reason, using contact lenses, and with a previous eye operation or drug use were excluded from the study. Serum thyroid stimulating hormone (TSH), free thyroxine (fT4) and free triiodothyronine (fT3) levels in addition to anti-thyroid peroxidase (anti-TPO) levels were studied from the blood samples taken at 08:00-09:00 in the morning following a 10-hour fasting period. This process was followed by thyroid ultrasonography (USG). Ultrasonography was used to support the diagnosis of HT. Ultrasonography by itself is not sensitive for the diagnosis of HT. When anti-TPO and/or anti-TG was positive in the serum in line with the presence of parenchymal heterogeneity on thyroid ultrasonography, Hashimoto's thyroiditis was diagnosed.

\section{Sampling}

We excluded the cases who reported topical cyclosporine, NSAID (locally/systemically) and steroid (locally/ systemically) use within the previous 6 months. Other exclusion reasons were contact lens wear, previous punctal plug, active ocular infection, use of other topical treatments, recurrent herpes keratitis within the last 6 months, blepharitis, ocular surgery or trauma within the last 6 months, punctate epithelial erosions of the cornea, other ocular surface diseases and non-keratoconjunctivitis sicca inflammation including atopic keratoconjunctivitis. No patient had a history of Stevens-Johnson syndrome; a thermal, chemical or radiation injury, or any other ocular surgery that would cause an ocular surface problem. Patients who had a history of systemic disease other than HT were excluded. Patients with HT had no signs and symptoms of dry eye. The controls had no ocular problems, no previous ocular surgery, and no major systemic disease that affects the ocular tissues. None of the patients or controls had a history of alcohol use or smoking. None of the patients with HT or those in the control group had a history of using diuretics, antihistamines, vitamins, anti-depressants, and any medications with anticholinergic properties.

Following the routine eye examinations, Schirmer's test was conducted with a standardized kit consisting of a strip of filter paper $5 \times 30-\mathrm{mm}^{2}$ in size that was placed on the lower lid margin in a temporal position. The patient looks up and blinks normally for 5 minutes, when the strip is removed and the wetted paper's length is measured. A value of $<5$ $\mathrm{mm}$ was considered abnormal and patients with abnormal results were excluded from the study.

Conjunctiva of the topically anaesthetized eye was subjected to impression cytology. Nelson graded conjunctival impression cytology specimens (grades 0-3) according to the number of goblet cells and the appearance of the epithelial cells (9). This grading score was used in the present study. Small disks of cellulose acetate filter paper (MFS, Advantec MFS, Pleasanton, USA, pore size $0.2 \mu \mathrm{m}$ ) were divided into pieces approximately $4 \mathrm{~mm} \times 5 \mathrm{~mm}$ in size, placed on the superior temporal interpalpebral conjunctiva at a $5 \mathrm{~mm}$ distance to the limbus, softly pressed for 5 seconds, and then lifted. After placing in a fixative solution, the relevant specimens were stained with Papanicolau's modification of Gill's technique. A pathologist who was masked to the history of each specimen examined the specimens with light microscopy. Employing Nelson's method, the examination recorded the appearance of conjunctival epithelial cells and goblet cells (if any) $(9,10)$. All slides were examined by two observers, similarly masked. All specimens were graded according to the following four-levels. Grade 0: the epithelial cells are small and round with eosinophilic-staining cytoplasm. The nuclei's nucleocytoplasmic ratio is 1:2, which is large. The goblet cells are ample, fleshy and oval with strongly Periodic Acid Schiff (PAS)-positive cytoplasm (Figure 1). Grade I: slightly larger epithelial cells than those in grade 0 and more polygonal, with eosinophilic-staining cytoplasm. Smaller nuclei with a nucleocytoplasmic ratio of 1:3 are evident. Fewer number of goblet cells appear; nevertheless, their plump, oval shape with strongly PASpositive cytoplasm are still maintained (Figure 2). Grade 
II: the epithelial cells are larger than those in grade I and polygonal, occasionally multinucleated, with an eosinophilic-staining cytoplasm. Their nucleocytoplasmic ratio is $1: 4$ to $1: 5$. The goblet cells are significantly fewer in number and are minor, insufficiently defined and less strongly PAS-positive (Figure 3). Grade III: the epithelial cells are larger than those in grade II and polygonal with a basophilic-staining cytoplasm. The nuclei are small, pycnotic, or completely absent in many cells. The goblet cells are completely non-existent (Figure 4).

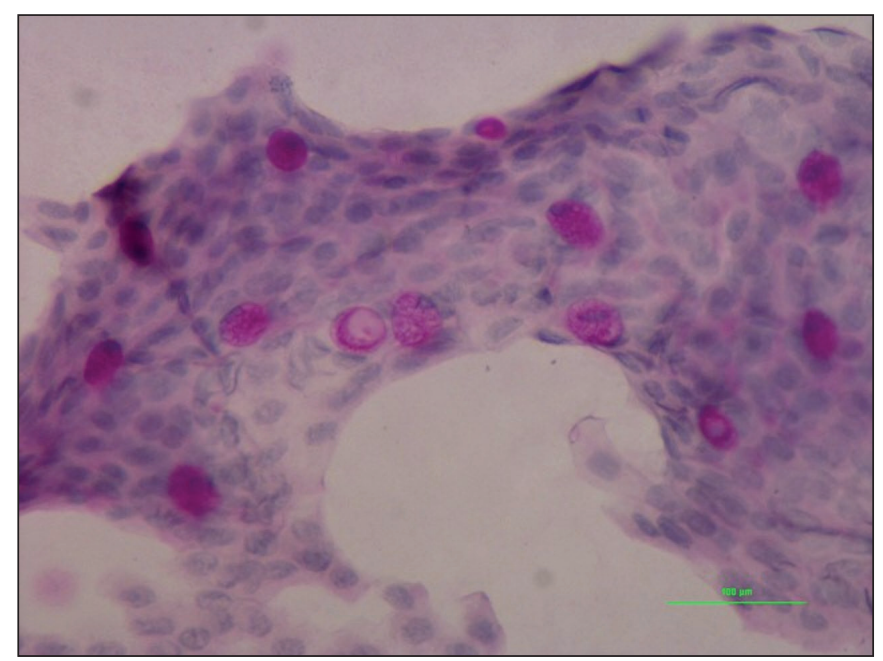

Figure 1: Grading system of impression cytology. Grade 0: small, ground epithelial cells have a prominent nucleus (PAS stain; $\mathrm{x} 400)$.

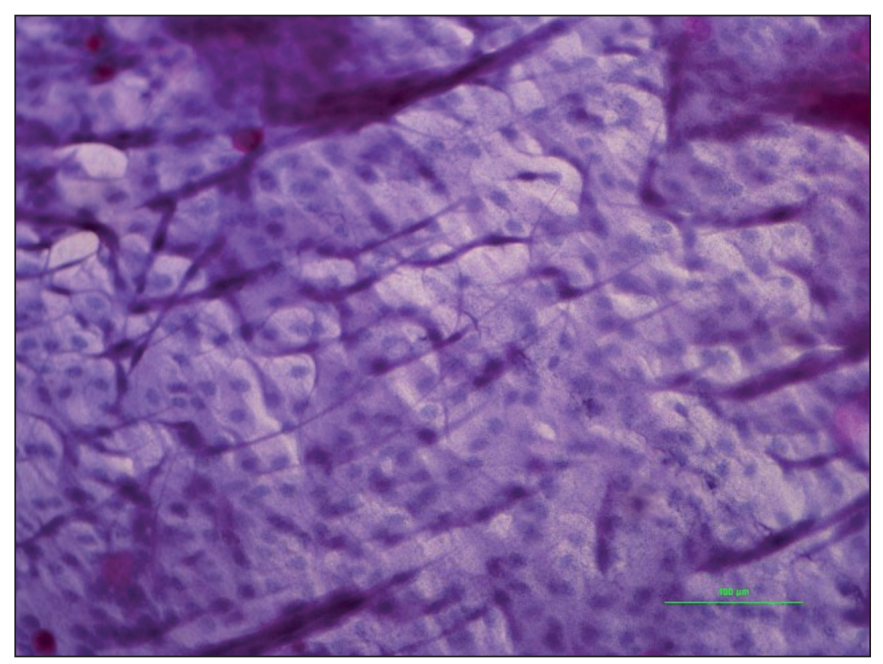

Figure 3: Grading system of impression cytology. Grade 2: larger and polygonal epithelial cells (N/C ratio 1:4-1:5). Goblet cells are smaller and markedly decreased (PAS stain; x200).

\section{Statistical Analysis}

Statistical evaluation was done with the Statistical Package for Social Sciences for Windows 20 (IBM SPSS Inc., Chicago, IL). Normal distribution of data was evaluated with the Kolmogorov-Smirnov test. Average\&standard deviation was calculated from the numerical variables showing normal distribution, and those not showing deviation have been represented as median (min-max). Categorical variables have been shown in numbers and percentages. Differentiation between HT and the control group has been

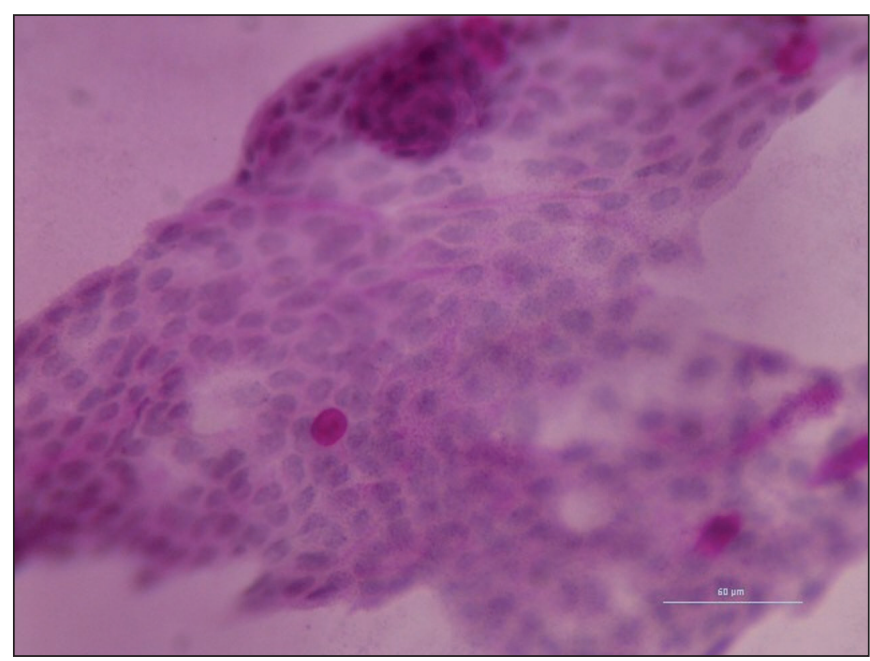

Figure 2: Grading system of impression cytology. Grade 1: the epithelial cells are slightly larger. The nuclei are smaller. Goblet cells are decreased minimally (PAS stain; x200).

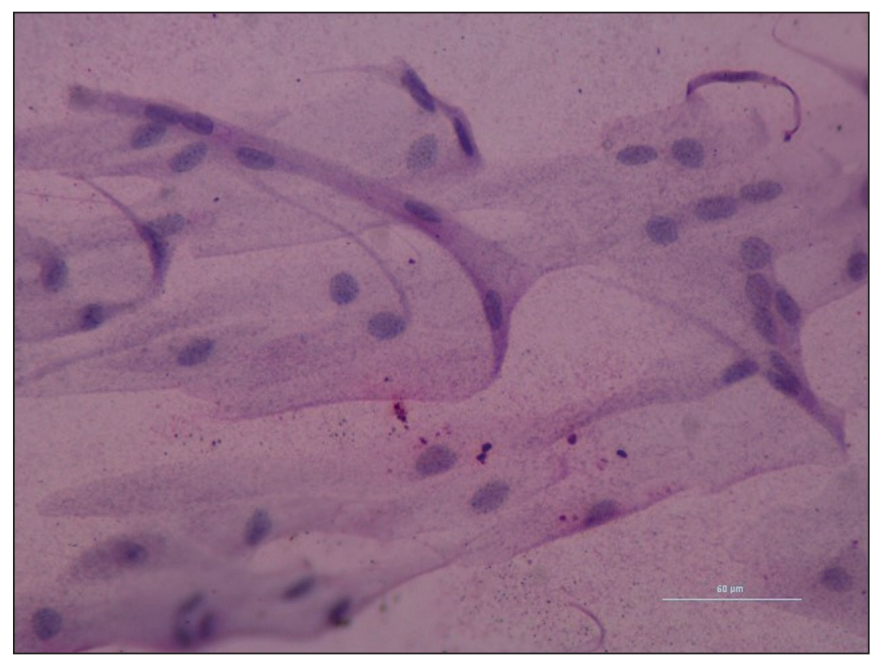

Figure 4: Grading system of impression cytology. Grade 3: goblet cells have disappeared (N/C ratio 1:6) (PAS stain; $\mathrm{x} 400$ ). 
cross-referenced as necessary with the Mann-Whitney U test, Student's t-test, Hashimoto's thyroid and Fisher's exact chi-square test. The differentiation between grade groups was tested with the ANOVA test, Kruskal-Wallis $\mathrm{H}$ and Monte Carlo chi-square with simulation. Possible independent predictors over grade 2-3 risk were tested with stepwise logistic regression analysis. $\mathrm{p}<0.05$ was accepted as statistically significant in all comparisons.

In the Nelson system, grade 0-1 was accepted as normal and grade 2 and 3 is accepted as abnormal (squamous metaplasia) $(4,7)$. While statistical analyses were being done, the grades which were normal (grade 0 and 1) and those which were abnormal (grade 2 and 3 ) were therefore separated into two groups and analyses were performed.

\section{RESULTS}

The research population was formed from a total of 58 participants, 25 of which were in the HT group, and 33 were the healthy volunteers. Demographic and clinical data pertaining to both groups have been depicted in Table I. Among HT patients, $12 \%(\mathrm{n}=3)$ were found to have Grade 0, 40\% ( $\mathrm{n}=10)$ had Grade 1, 28\% $(\mathrm{n}=7)$ had Grade 2, and
$20 \%(\mathrm{n}=5)$ had Grade 3. HT patients were observed to have an increase as compared to normal patients as the grade level increased $(\mathrm{p}<0.001)$. Abnormal CIC findings were found at a rate of $48 \%$ in the HT group while this figure was $6.1 \%$ in the control group $(\mathrm{p}<0.001)$.

The obesity rate in Grade 3 cases was higher than in the other grades ( $\mathrm{p}=0.003)$. In addition, in Grade 3 cases, the median TSH $(1.7 \mu \mathrm{IU} / \mathrm{mL}$ vs. $2.8 \mu \mathrm{IU} / \mathrm{mL}$ vs. $2.1 \mu \mathrm{IU} / \mathrm{mL}$ vs. $12.1 \mu \mathrm{IU} / \mathrm{mL} ; \mathrm{p}=0.003)$ was higher as compared to other TSH grades while the median sT4 (1 ng/dL vs. $1 \mathrm{ng} /$ dL vs. $1 \mathrm{ng} / \mathrm{dL}$ vs. $0.7 \mathrm{ng} / \mathrm{dL}$; $\mathrm{p}=0.041$ ) was lower. The antiTPO level was higher in Grade 3 cases as opposed to Grade 1-2 cases, while the anti-TPO level showed uniformity in Grade 1-2 cases (Figure 5). All the Grade 3 cases were found to be formed of HT patients (Table II).

The average BMI level in Grade 2-3 cases was higher than in Grade $0-1$ cases $\left(25.5 \pm 3.7 \mathrm{~kg} / \mathrm{m}^{2}\right.$ vs. $28.6 \pm 4.5 \mathrm{~kg} /$ $\left.\mathrm{m}^{2} ; \mathrm{p}=0.015\right)$. Also, while $42.9 \%$ of grade $2-3$ cases were obese, $9.1 \%$ of grade $0-1$ cases were obese $(p=0,020)$. The Hashimoto's thyroiditis rate in Grade 2-3 cases was much higher compared to grade $0-1$ cases $(29.5 \%$ vs. $85.7 \%$; $p<$

Table I: Demographic and clinical features of patients and controls.

\begin{tabular}{lccc}
\hline \multicolumn{1}{c}{ Variables } & $\begin{array}{c}\text { Control } \\
(\mathbf{n}=\mathbf{3 3})\end{array}$ & $\begin{array}{c}\text { Hashimoto Thyroiditis } \\
(\mathbf{n = 2 5})\end{array}$ & $\mathbf{p}$ \\
\hline Gender, $\mathrm{n}(\%)$ & $26(78.8)$ & $22(88.0)$ & 0.490 \\
\hline Female & $7(21.2)$ & $3(12.0)$ & $0.007^{*}$ \\
\hline Male & $34.7 \pm 5.4$ & $39.8 \pm 8.5$ & 0.461 \\
\hline Age $($ year $)$ & $1.6 \pm 0.1$ & $1.6 \pm 0.1$ & $0.006^{*}$ \\
\hline Height $(\mathrm{m})$ & $64.2 \pm 9.4$ & $73.6 \pm 15.2$ & $0.003^{*}$ \\
\hline Weight $(\mathrm{kg})$ & & $28.0 \pm 5.3$ & $<0.001^{*}$ \\
\hline BMI $\left(\mathrm{kg} / \mathrm{m}^{2}\right)$ & $24.9 \pm 2.3$ & $9(36.0)$ & $<0.001^{*}$ \\
\hline$<25$ & $15(45.5)$ & $6(24.0)$ & $0.002^{*}$ \\
\hline $25-30$ & $18(54.5)$ & $10(40.0)$ & $<0.001^{*}$ \\
\hline$>30$ & $1.6(0.5-3.0)$ & $5.7(0.9-89.0)$ & \\
\hline TSH $(\mu \mathrm{IU} / \mathrm{mL})$ & $1.0(0.6-1.9)$ & $0.8(0.4-1.3)$ & \\
\hline FT4 $(\mathrm{ng} / \mathrm{dL})$ & $13(2-16.8)$ & $59.3(1-1842)$ & $<0.001^{*}$ \\
\hline Anti TPO $(\mathrm{IU} / \mathrm{mL})$ & & $3(12.0)$ & \\
\hline Grade, $\mathrm{n}(\%)$ & $23(69.7)$ & $10(40.0)$ & $7(28.0)$ \\
\hline 0 & $8(24.2)$ & $5(20.0)$ & \\
\hline 1 & $2(6.1)$ & - & \\
\hline 2 & & & \\
\hline 3 & & & \\
\hline
\end{tabular}

${ }^{*} \mathrm{p}<0.05$ shows statistical significance.

BMI: body mass index, TSH: thyroid stimulating hormone, FT4: free thyroxine, Anti TPO: anti thyroid peroxidase. 
0.001). The median anti-TPO rate was higher in Grade 2-1 cases compared to the other grades $(14 \mathrm{IU} / \mathrm{mL}$ vs. $57.8 \mathrm{IU} /$ $\mathrm{mL} ; \mathrm{p}=0.001)$. Other demographic and clinical findings did not yield a significant difference (Table III).

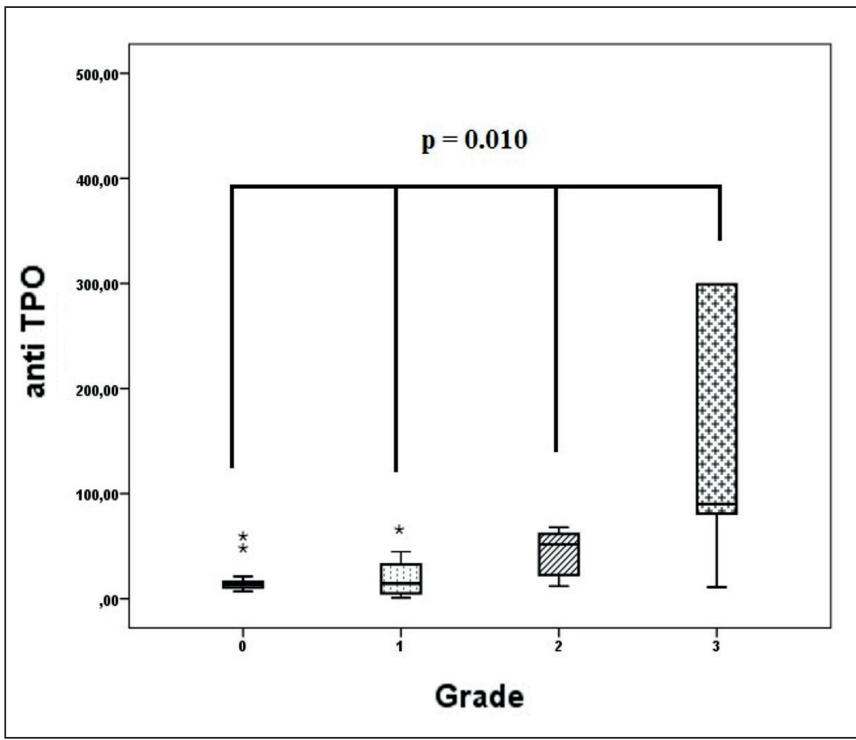

Figure 5: Anti TPO levels by CIC grade (Anti TPO unit: IU/mL) Anti TPO: Anti thyroid peroxidase, CIC: Conjunctival impression cytology.
Identification of independent predictors that may be effective on Grade 2-3 was done with the regression model formed from variables with a $\mathrm{p}$ value below 0.25 as found in Table III. Accordingly, it was identified that obesity (OR $=7.500 ; \mathrm{p}=0.017)$ and anti-TPO level $(\mathrm{OR}=1.370, \mathrm{p}=$ 0.007 ) is an independent predictor for Grade 2-3 (Table IV).

\section{DISCUSSION}

In the present study we found that conjunctival squamous metaplasia was more frequently seen in HT than controls and serum Anti-TPO level and BMI were detected as the independent predictors of the worsening of conjunctival impression cytology findings.

Impression cytology refers to the application of a cellulose acetate filter to the ocular surface to remove the ocular surface epithelium's superficial layers. The removed cells can thus be subjected to immune-histological, histological, or molecular analysis. It is easy to perform and noninvasive, and provides reliable information regarding the area sampled with minimal discomfort to the patient. Therefore, it is a fundamental method in understanding ocular surface disorders. Impression cytology applications can be used for the aetiological diagnosis of various ocular

Table II: Demographic and clinical features of all participant according to Grading system.

\begin{tabular}{|c|c|c|c|c|c|}
\hline \multirow{2}{*}{ Variables } & \multicolumn{4}{|c|}{ Grade } & \multirow[b]{2}{*}{$\mathbf{p}$} \\
\hline & 0 & 1 & 2 & 3 & \\
\hline \multicolumn{6}{|l|}{ Gender, n(\%) } \\
\hline Female & $20(76.9)$ & $15(83.3)$ & $8(88.9)$ & $5(100)$ & \multirow{2}{*}{0.764} \\
\hline Male & $6(23.1)$ & $3(16.7)$ & $1(11.1)$ & $0(0)$ & \\
\hline Age (year) & $34.7 \pm 6.5$ & $38.4 \pm 7.6$ & $38.7 \pm 8.4$ & $39.6 \pm 7.3$ & 0.237 \\
\hline Height (m) & $1.6 \pm 0.1$ & $1.6 \pm 0.1$ & $1.6 \pm 0.1$ & $1.6 \pm 0.1$ & 0.990 \\
\hline Weight $(\mathrm{kg})$ & $65 \pm 10.2$ & $70.6 \pm 15.7$ & $64 \pm 12$ & $82 \pm 4.5$ & $0.027^{\star}$ \\
\hline BMI $\left(\mathrm{kg} / \mathrm{m}^{2}\right)$ & $24.7 \pm 2.4$ & $26.7 \pm 4.9$ & $26.5 \pm 4.1$ & $32.3 \pm 2.4$ & $0.003^{\star}$ \\
\hline$<25$ & $11(42.3)$ & $9(50.0)$ & $4(44.4)$ & - & \multirow{3}{*}{$0.001^{\star}$} \\
\hline $25-30$ & $15(57.7)$ & $5(27.8)$ & $3(33.3)$ & $1(20.0)$ & \\
\hline$>30$ & - & $4(22.2)$ & $2(22.2)$ & $4(80.0)$ & \\
\hline $\mathrm{TSH}(\mu \mathrm{IU} / \mathrm{mL})$ & $1.7(0.5-31.1)$ & $2.8(0.5-32.0)$ & $2.1(0.7-7.1)$ & $12.1(5.7-89.0)$ & $0.003^{\star}$ \\
\hline FT4 (ng/dL) & $1.0(0.6-1.9)$ & $1.0(0.5-1.5)$ & $1.0(0.7-1.2)$ & $0.7(0.4-0.8)$ & $0.041^{\star}$ \\
\hline Anti TPO (IU/mL) & $13.8(7-59.3)$ & $14.5(1-325)$ & $51.7(2-1769)$ & $90(1-1842)$ & $0.010^{\star}$ \\
\hline \multicolumn{6}{|l|}{ Group, n(\%) } \\
\hline Control & $23(88.5)$ & $8(44.4)$ & $2(22.2)$ & $0(0)$ & \multirow{2}{*}{$<0.001^{\star}$} \\
\hline Hashimoto's thyroiditis & $3(11.5)$ & $10(55.6)$ & $7(77.8)$ & $5(100)$ & \\
\hline
\end{tabular}

${ }^{*} p<0.05$ shows statistical significance.

BMI: Body mass index, TSH: Thyroid stimulating hormone, FT4: Free thyroxine, Anti TPO: Anti thyroid peroxidase. 
surface disorders, documenting sequential changes in the conjunctival and corneal surface over time, monitoring the treatment effects and staging conjunctival squamous metaplasia, and as a useful tool for analyzing ocular surface disease with immunostaining and DNA analysis (10).

Normal conjunctiva has a non-keratinized stratified epithelium. This layer is necessary to keep the surface smooth. Modification of the stratified non-keratinized secretory epithelium to non-secretory keratinized epithelium is called squamous metaplasia $(10,11)$. It has been reported that squamous metaplasia is seen in many eye diseases that go with inflammation (dry eye, atopic conjunctivitis) and systemic diseases (10,11). Inflammation and loss of vascularization with regards to scar tissue have been proposed as the causes of squamous metaplasia (10). We previously reported that increased duration of chronic renal failure increases the risk of metaplasia depending on the degree of inflammation (12). The mechanism of the loss of goblet cells due to vascularization and inflammation remains unclear.

Table III: Demographic and clinical features of all study populations according to Grade 0-1 / 2-3.

\begin{tabular}{|c|c|c|c|}
\hline Variables & Grade 0-1 & Grade 2-3 & $\mathbf{p}$ \\
\hline \multicolumn{4}{|l|}{ Gender, $\mathrm{n}(\%)$} \\
\hline Female & $35(79.5)$ & 13(92.9) & \multirow{2}{*}{0.424} \\
\hline Male & $9(20.5)$ & $1(7.1)$ & \\
\hline Age (year) & $36.2 \pm 7.1$ & $39 \pm 7.8$ & 0.218 \\
\hline Height $(\mathrm{m})$ & $1.6 \pm 0.1$ & $1.6 \pm 0.1$ & 0.902 \\
\hline Weight $(\mathrm{kg})$ & $67.3 \pm 12.8$ & $70.4 \pm 13.2$ & 0.431 \\
\hline BMI $\left(\mathrm{kg} / \mathrm{m}^{2}\right)$ & $25.5 \pm 3.7$ & $28.6 \pm 4.5$ & $0.015^{\star}$ \\
\hline$<25$ & $20(45.5)$ & $4(28.6)$ & \multirow{3}{*}{$0.020^{*}$} \\
\hline $25-30$ & $20(45.5)$ & $4(28.6)$ & \\
\hline$>30$ & $4(9.1)$ & $6(42.9)$ & \\
\hline $\mathrm{TSH}(\mu \mathrm{IU} / \mathrm{mL})$ & $2.0(0.5-32)$ & $2.6(0.7-89.0)$ & 0.136 \\
\hline FT4 (ng/dL) & $1.0(0.5-1.9)$ & $0.9(0.4-1.2)$ & 0.093 \\
\hline Anti TPO (IU/mL) & $14(1-325)$ & $57.8(11-1842)$ & $0.001^{*}$ \\
\hline \multicolumn{4}{|l|}{ Group } \\
\hline Control, n(\%) & $31(70.5)$ & $2(14.3)$ & \multirow{2}{*}{$<0.001^{\star}$} \\
\hline Hashimoto's thyroiditis, $\mathrm{n}(\%)$ & $13(29.5)$ & $12(85.7)$ & \\
\hline
\end{tabular}

${ }^{*} p<0.05$ shows statistical significance.

BMI: Body mass index, TSH: Thyroid stimulating hormone, FT4: Free thyroxine, Anti TPO: Anti thyroid peroxidase.

Table IV: Independent predictors of Grade 2-3 risk.

\begin{tabular}{|c|c|c|c|c|}
\hline \multirow{2}{*}{ Variables } & \multirow{2}{*}{ OR } & \multicolumn{2}{|c|}{ 95\% CI } & \multirow[b]{2}{*}{$\mathbf{p}$} \\
\hline & & lower & upper & \\
\hline \multicolumn{5}{|l|}{ BMI } \\
\hline$<25$ & ref & ref & ref & ref \\
\hline $25-30$ & 1.000 & 0.219 & 4.564 & 0.999 \\
\hline $30 \leq$ & 7.500 & 1.427 & 39.414 & $0.017^{\star}$ \\
\hline Anti TPO & 1.370 & 1.100 & 1.660 & $0.007^{\star}$ \\
\hline \multicolumn{5}{|c|}{ Nagelkerke $R^{2}=0.389 . p<0.001$} \\
\hline
\end{tabular}

${ }^{*} p<0.05$ shows statistical significance.

Regression model was created with the variables in Table III and with p values below 0.25

BMI: Body mass index, Anti TPO: Anti thyroid peroxidase. 
According to recent studies, thyroid hormone deficiency predisposes to structural changes of the ocular surface and dry eye (13). It has been demonstrated that the lacrimal gland is a target organ for thyroid hormone and expresses thyroid hormone receptor $\beta-1$ (Thrb). In rats, it has been proven that chronically reduced thyroid hormone levels modulate the expression of Thrb in the lacrimal gland and can therefore cause dry eye (13). To the best of our knowledge, there are only a few studies that have investigated the association between thyroid diseases and CIC. First, Özkan et al. reported in 1997 a much higher rate (82.3\%) of Grade 2 and 3 conjunctival changes in TAO (11). They investigated the association between TAO and CIC. Only two components of TAO listed as increased interpalpebral distance and proptosis had a weak relation with squamous metaplasia, and inflammation was the primary reason for these changes. Thereafter similar ocular surface changes were found in several studies on Graves' disease. For example, İsmailova et al. detected worsening conjunctival structure in $\mathrm{TAO}$ by using impression cytology, vital staining and incisional biopsy methods $(6,7,14,15)$. They state that vital staining may indicate absence of transmembrane and secretory mucin that protects the superficial epithelial cells. They speculated that this glycoprotein deficiency (clinically identified by vital staining) may cause or worsen secondary damage of both the superficial epithelial cells and the deeper epithelial cells (15). In another study, Gürdal et al. found an increased rate (75.7\%) of Grade 2 and 3 CIC changes in Graves' disease. In subgroup analysis, Grade 2-3 changes were similar in Graves' disease with-or-without TAO (6). They evaluated TAO clinically in GD patients and 24 of 42 eyes (57\%) were diagnosed with TAO. Eighteen eyes did not have a clinical diagnosis of TAO but had the signs of dry eye and higher grades of squamous metaplasia similar to the eyes with TAO. These patients signified ocular surface inflammation before the classic signs of the disease developed. The authors emphasized that inflammation was the main factor for these changes. Even so, before the onset of overt findings of TAO, ocular surface inflammation (Grade 2-3 changes of CIC) can be the single clinical sign in Graves' disease $(6,7)$. Inflammation is reported to be $\mathrm{T}$ cell mediated and pro-inflammatory agents like IL-1, MMP-9 and TNF-alpha are also associated with it $(6,7,14)$. Similarly Gupta et al. reported dry eye in occult TAO, which was diagnosed by orbital echography in the dry eye patients with no classic clinical findings of TAO such as exophthalmos and lid retraction (16). Interestingly enough, we spotted squamous metaplasia changes in half of the HT patients without TAO or dry eye findings or any eye symptoms. This has not previously been reported in the literature. To top it off, the increase of TSH in patients with Grade 3 changes has been proven to be related to the drop in fT4. Perhaps most importantly, the CIC levels of HT patients whose anti TPO levels were high became worse. In the above mentioned studies, Grade 2-3 metaplasia is reported to be usually seen with dry eyes, and inflammation is held responsible for both of these conditions. However, we have seen that CIC grade was higher in HT patients despite the fact that none of our patients had dry eyes. The CIC Grade became worse as autoantibodies (Anti-TPO) increased according to the results of our study. This suggested that autoantibodies could be held responsible for the development of conjunctival metaplasia in HT as we know that TSHR, a thyroid autoantibody, plays an important role in Graves' ophthalmopathy (17). The well-known association between high levels of thyroid autoantibodies and inflammation also contributes to this conclusion (18). Similarly, we found that Grade 2-3 changes were significantly higher in obese people and obesity was determined as an independent predictor for grade worsening which made us think that fat tissue gain had a role in the pathogenesis. We know that release of pro-inflammatory cytokines due to the increase of fat tissue and also of immune-modulatory factors due to insulin resistance are seen in obesity and that these molecules may cause inflammation and squamous metaplasia in conjunctiva as they do in other tissues and organs (19). However there is no study providing information about the obesity-CIC association.

The higher rate of Grade 2-3 changes in patients compared to the control group with even dry eye patients were excluded. This suggests that the triggering factors of eye inflammation in HT might be different from Graves' ophthalmopathy. We think further research is definitely needed on this topic.

There were some limitations in our study. Firstly, the number of patients is relatively small. Secondly, other thyroid autoantibodies (i.e. anti-TG, TSHR) and cytokines (such as IL-1 and TNF- $\alpha$ ) that can possibly play a role in conjunctival squamous metaplasia pathogenesis were not studied.

In conclusion, this is the first study to show that the conjunctiva is affected in HT distinct from TAO and dry eye. Anti-TPO levels and obesity were possible triggering factors in this process. We need early detection of conjunctival changes before the development of ophthalmopathy in patients with Hashimoto's thyroiditis because early detection may prevent ophthalmopathy complications such as blindness. 


\section{CONFLICT of INTEREST}

The authors declare no conflict of interest.

\section{REFERENCES}

1. Mikos H, Mikos M, Obara-Moszynska M, Niedziela M. The role of the immune system and cytokines involved in the pathogenesis of autoimmune thyroid disease (AITD). Endokrynol Pol. 2014; 65: $150-5$.

2. Tunbridge WM, Vanderpump MP. Population screening for autoimmune thyroid disease. Endocrinol Metab Clin North Am. 2000; 29: 239-53.

3. Devendra D, Eisenbarth GS. 17. Immunological endocrine disorders. J Allergy Clin Immunol. 2003; 111: 624-36.

4. Kan E, Kan EK, Ecemis G, Colak R. Presence of thyroid-associated ophthalmopathy in Hashimoto's thyroiditis. Int J Ophthalmol. 2014; 7: 644-7.

5. Kan E, Kılıçkan E, Ecemiş G, Beyazyildiz E, Çolak R. Presence of dry eye in patients with Hashimoto's Thyroiditis. J Ophthalmol. $2014 ; 754923$.

6. Gürdal C, Saraç O, Genç I, Kırımlıoğlu H, Takmaz T, Can I. Ocular surface and dry eye in Graves' disease. Curr Eye Res. 2011; 36: 8-13.

7. Kocabeyoglu S, Mocan MC, Cevik Y, Irkec M. Ocular surface alterations and in vivo confocal microscopic features of corneas in patients with newly diagnosed Graves' disease. Cornea. 2015; 34: 745-9.

8. Bahn RS, Burch HB, Cooper DS, Garber JR, Greenlee MC, Klein I, Laurberg P, McDougall IR, Montori VM, Rivkees SA, Ross DS, Sosa JA, Stan MN, American Thyroid Association; American Association of Clinical Endocrinologists. Hyperthyroidism and other causes of thyrotoxicosis: Management guidelines of the American Thyroid Association and American Association of Clinical Endocrinologists. Endocr Pract. 2011; 17: 456-520.
9. Doughty MJ. Assessment of consistency in assignment of severe (Grade 3) Squamous Metaplasia to Human Bulbar conjunctiva impression cytology cell samples. Ocul Surf. 2015; 13: 284-97.

10. Singh R, Joseph A, Umapathy T, Tint NL, Dua HS. Impression cytology of the ocular surface. Br J Ophthalmol. 2005; 89: 1655-9.

11. Özkan SB, Söylev MF, Vahapoglu H, Can D, Arsan AK, Duman S. Evaluation of conjunctival morphology in thyroid associated eye disease by use of impression cytology. Acta Ophthalmol Scand. 1997; 75: 145-7.

12. Demir N, Altay M, Ozer Demir N, Altay M, Ozer E, Unlü N, Duranay M, Ustün H, Duman S. Duration of renal failure as risk factor for conjunctival squamous metaplasia. Acta Cytol. 2008; 52: 309-12.

13. Dias AC, Módulo CM, Jorge AG, Braz AM, Jordao AA Jr, Filho $\mathrm{RB}$, de Paula JS, Rocha EM. Infuence of thyroid hormone on thyroid hormone receptor $\beta$-1expression and lacrimal gland and ocular surface morphology. Invest Ophthalmol Vis Sci. 2007; 48: 3038-42.

14. de Almeida SF, de Sousa LB, Vieira LA, Chiamollera MI, Barros Jde N. Clinic-cytologic study of conjunctivochalasis and its relation to thyroid auto immune diseases: Prospective cohort study. Cornea. 2006; 25: 789-93.

15. Ismailova DS, Fedorov AA, Grusha YO. Ocular surface changes in thyroid eye disease. Orbit. 2013; 32: 87-90.

16. Gupta A, Sadeghi PB, Akpek EK. Occult thyroid eye disease in patients presenting with dry eye symptoms. Am J Ophthalmol. 2009; 147: 919-23.

17. Garrity JA, Bahn RS. Pathogenesis of Graves ophthalmopathy: Implications for prediction, prevention, and treatment. Am J Ophthalmol. 2006; 142: 147-53.

18. Chistiakov DA. Immunogenetics of Hashimoto's thyroiditis. J Autoimmune Dis. 2005; 2:1

19. Chen L, Chen R, Wang H, Liang F. Mechanisms linking inflammation to insulin resistance. Int $\mathrm{J}$ Endocrinol. 2015;2015:508409. 